\title{
Competitive Adsorption of Xylene and Toluene on Modified and Unmodified Magnesium Exchanged Bentonite Clay Mineral
}

\author{
*CHIKWE, TN; EWUZIE, HE; NGOBIRI, NC; OKOYE, IP
}

\author{
Department of Pure and Industrial Chemistry, University of Portharcourt, Rivers State, Nigeria
}

*Email:templechikwe@yahoo.co.uk)

\begin{abstract}
Cetyltrimethylammonium bromide (CTAB) - modified and unmodified magnesium exchanged bentonite were used for the competitive adsorption of $\mathrm{m}$-xylene and toluene from their aqueous solution. Infrared spectroscopy (IR, adsorption capacity and Foster swelling measurements were performed using Fourier Transform Infrared Spectrophotometer to evaluate the performance of the adsorbents. The FT-IR results indicated that the quaternary ammonium salts (Cetyltrimethylammonium bromide) were intercalated between the layers of the bentonite clay. The Foster swelling test results indicated that the affinity of CTAB occurred in the treated clay as tested in all organic solvents (diesel, kerosene, gasoline, toluene and $\mathrm{m}$-xylene), with and without agitation. The result showed that modified magnesium bentonite swelled more than the unmodified and the order of the swelling factor is; $\mathrm{m}$ - xylene $>$ toluene $>$ gasoline $>$ diesel $>$ DPK $>$ water. However, when the assay was performed under agitation, it yielded higher swelling capacity and all the organic solvents used in this investigation showed good compatibility after organophilization. The modified clay exhibited very high capacity of adsorption compared to unmodified samples. The $\mathrm{m}$-xylene and toluene uptake follows a pseudo second order kinetics mechanism, suggesting that the rate determining step of adsorption involves the two adsorbates competitively adsorbed on the adsorbent sites. Modified magnesium bentonite has a higher percentage removal and higher adsorption capacity than raw or unmodified magnesium bentonite. These adsorbents (modified magnesium bentonite) are therefore recommended for use by water treatment and petrochemical industries for removal of hydrocarbons ( $\mathrm{m}$ - xylene and toluene) from their waste water and effluents.
\end{abstract}

DOI: https://dx.doi.org/10.4314/jasem.v22i3.1

Copyright: Copyright (C) 2018 Ewuzie et al. This is an open access article distributed under the Creative Commons Attribution License (CCL), which permits unrestricted use, distribution, and reproduction in any medium, provided the original work is properly cited.

Dates: Received: 08 January 2018; Revised: 27 February: 2018; Accepted: 23 March 2018

Keywords: Bentonites, divitrification, organophilization, cetyltrimethylammonium bromide, swelling,

The discovery of bentonite has led to its usage and application in several areas such as petroleum industries, water industries, pharmaceutical companies, agriculture, foundry, medicine, paint industries and some others (Hosterman and Patterson, 1992). Bentonite is a clay mineral which is formed as a result of chemical alteration of the volcanic ash. It is also formed during the process of divitrification. Divitrification is a process whereby a crystalline compound or structure, grows on the surface of a glass. The primary and the rudiment components of bentonite are montmorillonite and a small amount of beidellite (Arthur and Robert, 2010). The amount of montmorillonite present will determine the properties of the bentonite. One important application of bentonite is its utilization in the water treatment for heavy metal removal and also for petrochemical removal from industrial effluents (Jorge et al., 2012). Bentonite is a hydrophilic compound and must be modified using a suitable modifying agent such as quaternary ammonium compound (QAC), in order to enhance its organophilic properties (Clarence and
Earl, 1926). Modification refers to the process of changing or altering the surface of a material or the surface of any substance by using physical, chemical or biological means so as to improve and enhance the original properties of the material or substance such as its surface area, it's adsorptive properties, it's pores and some other features, and by so doing making it fit for its anticipated purpose (Okoye et al., 2012). Petrochemical waste water do contain some pollutant such as phenol, heavy metals, benzene, toluene, ethylbenzene and xylene (BTEX) which must be removed using a suitable adsorbent before the water will be discharged in the water bodies. Bentonite is always preferred because of it low cost, its availability and its high adsorption capacity (Koyuncu et al., 2011). Natural bentonite exist in two forms which are calcium bentonite and sodium bentonite but other forms of bentonite such as magnesium bentonite, potassium bentonite, iron bentonite and aluminium bentonite could be synthesized from the natural forms of bentonite through ion exchange method or mechanism 
(Komlosi et al., 2007; Obi and Okoye, 2015). Studies have shown that modified bentonite is very effective in the removal of hydrocarbon and petrochemicals from waste water and aqueous solution than unmodified bentonite (Obi and Apemiye, 2017). The objective of this study is to determine the efficiency and the effectiveness of CTAB modified magnesium bentonite in the removal of m-xylene and toluene from aqueous solution. The effect of contact time, adsorbent and initial concentrations were evaluated.

\section{MATERIALS AND METHODS}

The sodium bentonite used for this study was obtained from Mansid Nigeria Limited, Portharcourt Rivers State, Nigeria. Magnesium chloride, cetyltrimethylammonium bromide, $\mathrm{m}$ - xylene and toluene were obtained from Sigma-Aldrich Company, Switzerland at $>98 \%$ purity, and were used as received without any purification. The petroleum product solvents were obtained from NNPC, Portharcourt, Rivers State, Nigeria.

Preparation of Magnesium Bentonite: Magnesium bentonite was prepared by Ion exchange method adopted by Thakre et al., 2010. A measured amount of $10 \mathrm{~g}$ of sodium bentonite was soaked in $200 \mathrm{ml}$ of water for 24 hours (overnight). Thereafter, $200 \mathrm{ml}$ of the $1 \mathrm{M}$ solution of magnesium chloride was added to the bentonite- water mixture. The mixture was stirred and refluxed at $75^{\circ} \mathrm{C}$ for a duration of 2 hours. Thereafter, it was filtered and was washed severally for the removal of excess chlorine present in the magnesium exchanged bentonite. The modification of the adsorbent was carried out following the method outlined by Bedin et al., 2013). The FT- IR analysis was carried out using Fourier transformed infrared spectrometer (model number IR AFFINITY -1) at a range of $400-4000 \mathrm{~cm}^{-1}$.

The Foster swelling test was carried out following the method by Paiva and Morales, 2012.

$F_{S B}=\frac{V_{B}-V_{I}}{V_{I}} \ldots \ldots \ldots \ldots$

$F_{F A}=\frac{V_{A}-V_{I}}{V_{I}} \ldots \ldots \ldots \ldots$

$F_{S B}$ and $F_{S A}$ are the swelling factor before and after agitation respectively, $V_{B}$ and $V_{A}$ are the volume of the adsorbent before and after agitation respectively, While $\mathrm{V}_{\mathrm{I}}$ is the initial volume of the adsorbent in the glass tube before solvent addition. This analysis was carried out in accordance with the method by Bandura et al., 2017.
The percentage removal $(\% \mathrm{R})$ and the adsorption Capacity $\left(\mathrm{q}_{\mathrm{e}}\right)$ are calculated using equation 3 and 4

$R(5)=\frac{C_{O}-C_{e}}{C_{O}} \times 100$

$q_{e}=\frac{C_{O}-C_{e}}{m} \times \mathrm{V}$

Where $\mathrm{q}_{\mathrm{e}}=$ adsorption capacity, $\% \mathrm{R}=$ percentage removal, $\mathrm{m}=$ mass of the adsorbent, $\mathrm{V}=$ volume of the adsorbate, $\mathrm{C}_{\mathrm{o}}$ and $\mathrm{C}_{\mathrm{e}}$ are the initial and final concentration of the adsorbate respectively (Nourmoradi et al., 2012; Senturk et al., 2009).

\section{RESULTS AND DISCUSSION}

Adsorbent Characterization: The adsorbents employed in this research were characterized for some important physicochemical parameters in the adsorption process.

FT- IR Analysis: The FT- IR spectral result of CTAB modified bentonite and natural bentonite is shown in figure 1. At $3400-3642 \mathrm{~cm}^{-1}$, a broad band was observed, which shows the presence of $\mathrm{O}-\mathrm{H}$ vibration of the water adsorbed silica surface (Sari et al., 2007). Another adsorption band appeared at $1640 \mathrm{~cm}^{-}$ 1 which shows the presence of $\mathrm{H}-\mathrm{O}-\mathrm{H}$ bending vibration whereas the broad band around $1011.1 \mathrm{~cm}^{-1}$ and $1038.1 \mathrm{~cm}^{-1}$ is related to the stretch vibration of $\mathrm{Si}-\mathrm{O}-\mathrm{Si}$ groups. With respect to the modified bentonite, the two peaks that appeared at $2985.64-$ $2860.02 \mathrm{~cm}^{-1}$ shows the presence of $-\mathrm{CH}_{3}$ and $-\mathrm{CH}_{2}$ stretching vibration respectively. A $\mathrm{H}-\mathrm{O}-\mathrm{H}$ deformation peak was also seen at $1566.92-1601 \mathrm{~cm}^{-}$ 1 (Eren, 2008). The presence of Cetyltrimethylammonium bromide in the modified magnesium bentonite is proved by the existence of methyl group and the methylene group strictly in the modified magnesium bentonite.

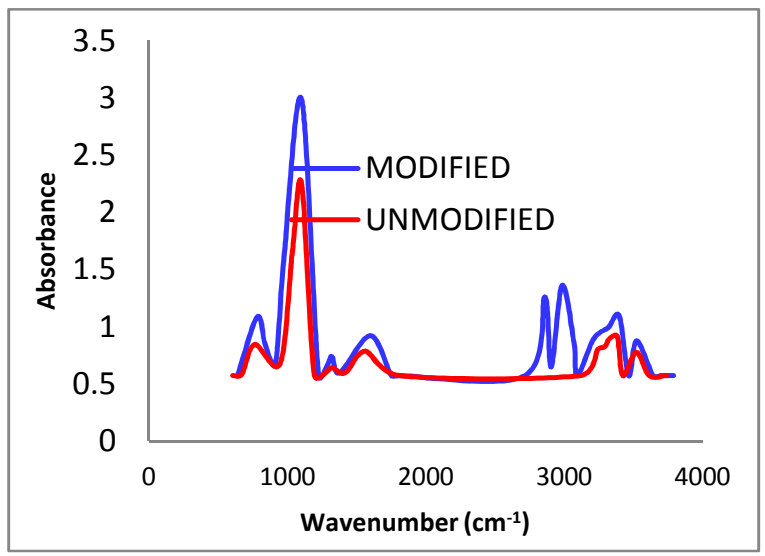

Fig 1: FT- IR spectral of (red) unmodified and (blue) CTAB modified magnesium bentonite 


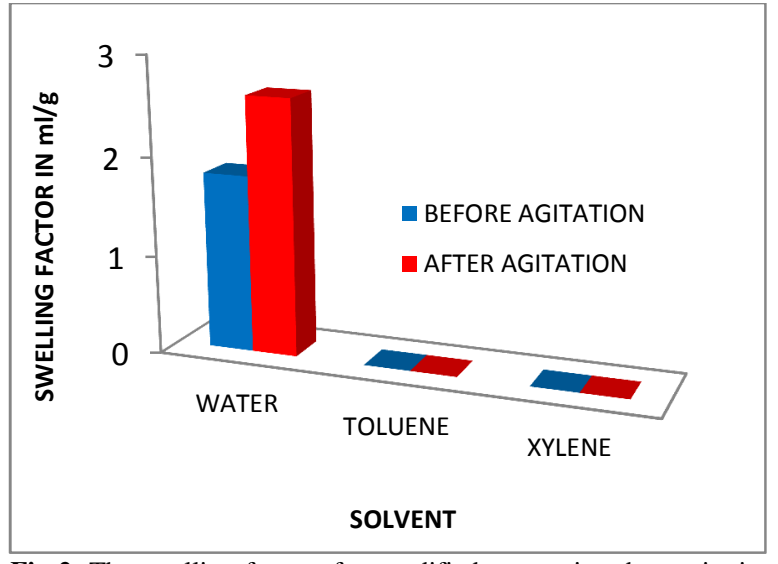

Fig 2: The swelling factor of unmodified magnesium bentonite in petrochemical solvent and water

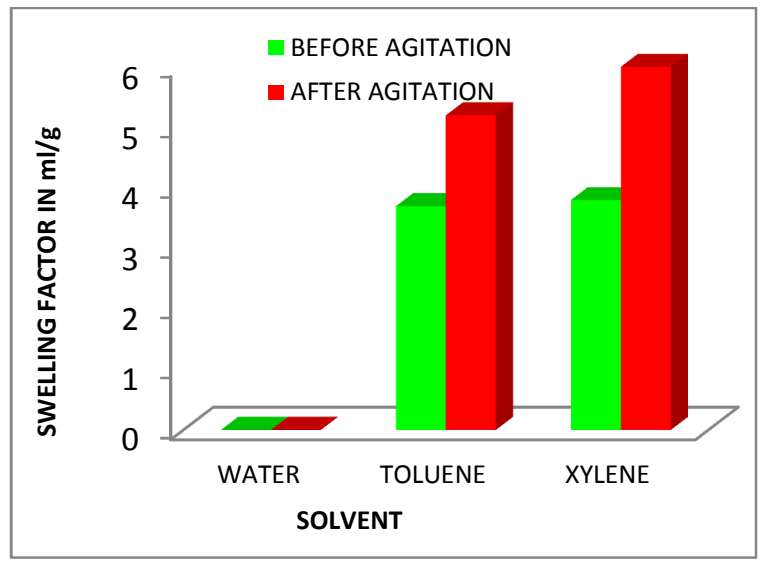

Fig 3: The swelling factor of modified magnesium bentonite in petrochemical solvent and water

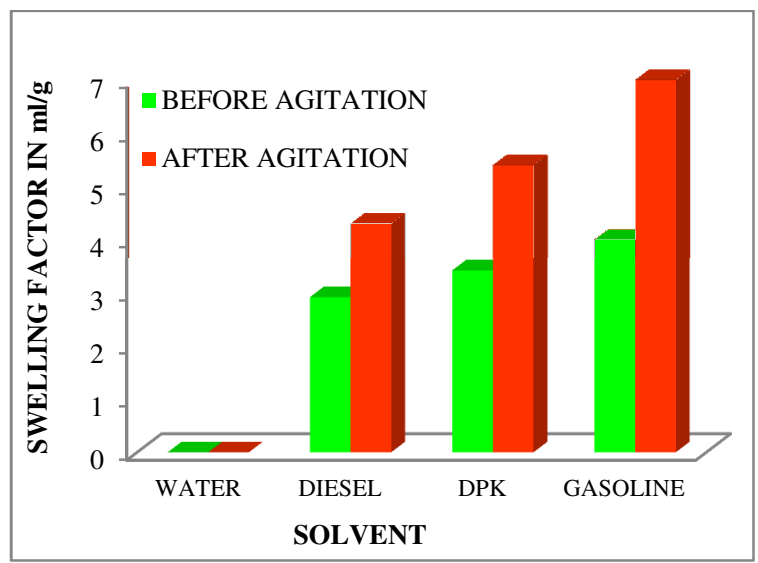

Fig. 4: The swelling factor of modified magnesium bentonite in petroleum product and water

Figure 2 to 5 shows the swelling factors of modified and unmodified magnesium bentonite. Modified magnesium bentonite obviously swelled to a volume higher than its original volume. The swelling factor increased as the CTAB concentration increased.

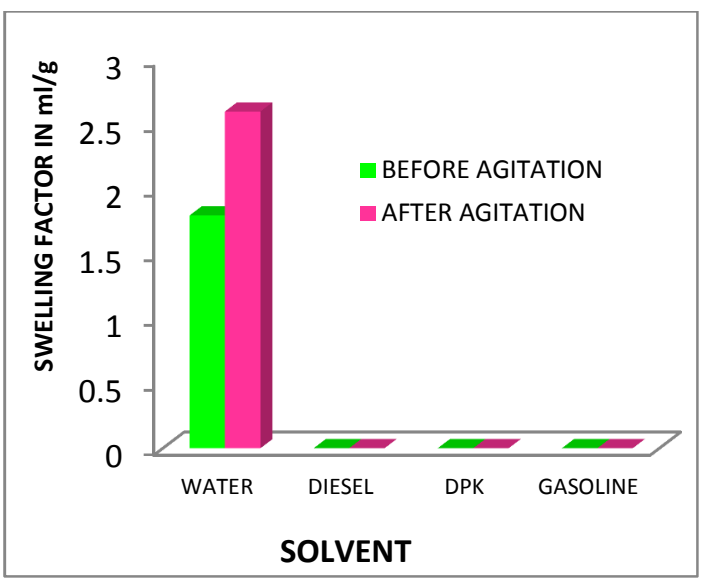

Fig 5: The swelling factor of unmodified magnesium bentonite in petroleum product and water

Modified magnesium bentonite swelled higher in petrochemical / hydrocarbon solvent ( $m$ - xylene and toluene) than in petroleum product solvents (diesel, DPK and gasoline) but completely failed to swell in water. Unmodified magnesium bentonite swelled in water but swelled neither in petrochemical / hydrocarbon solvents nor in petroleum product solvents. The swelling of clays in water occurs because of the capacity of the external and internal surfaces of the clay mineral layers to be hydrated. During the test, unmodified magnesium bentonite showed no swelling in any of the organic solvents investigated, as expected, the absence of swelling is due to the organophobic character of $\mathrm{Mg}$ - bentonite that does not permit interaction with the organic solvent. For the organophilic bentonite in contact with the organic solvents, the swelling occurred due to the diffusion of the molecules of the solvent between the clay mineral layers. This process is favored by the balance between the nature of the hydrocarbon solvents - compounds of low polarity, and the alkyl chains of the CTAB modifier that decrease the polarity of the clays (Paiva and Morales, 2012).

Figure 6 and 7 showed the adsorption capacity measurement of magnesium bentonite using organic solvents and water. The Modified bentonite adsorbed more of organic solvent than water whereas unmodified magnesium bentonite adsorbed more water than the organic solvent. The result of the adsorption capacity measurement in static condition is given as; $\mathrm{m}$ - xylene $>$ toluene $>$ gasoline $>$ diesel $>$ DPK > water. Unmodified magnesium bentonite adsorbed water due to the isomorphic substitution of the cation present in the octahedral lattice which 
results to excessive electrons on the bentonite surface.

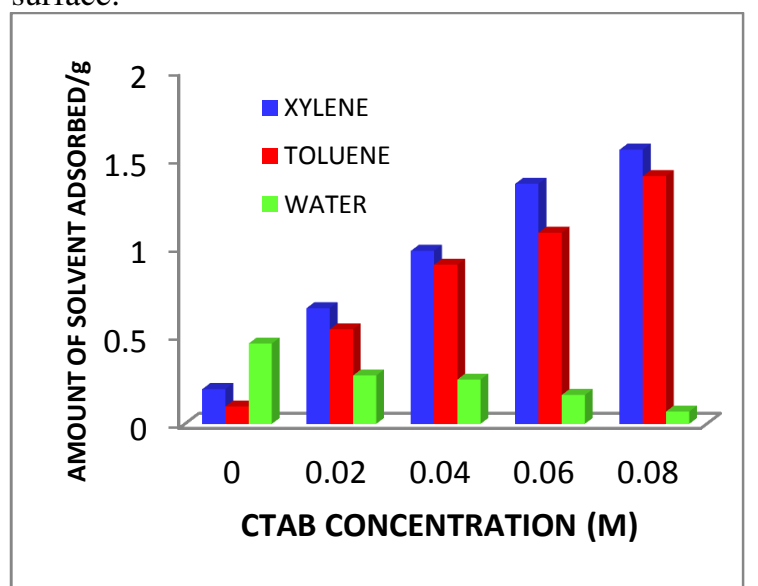

Fig 6: Effect of CTAB concentration on the adsorption capacity of magnesium bentonite using hydrocarbon and water

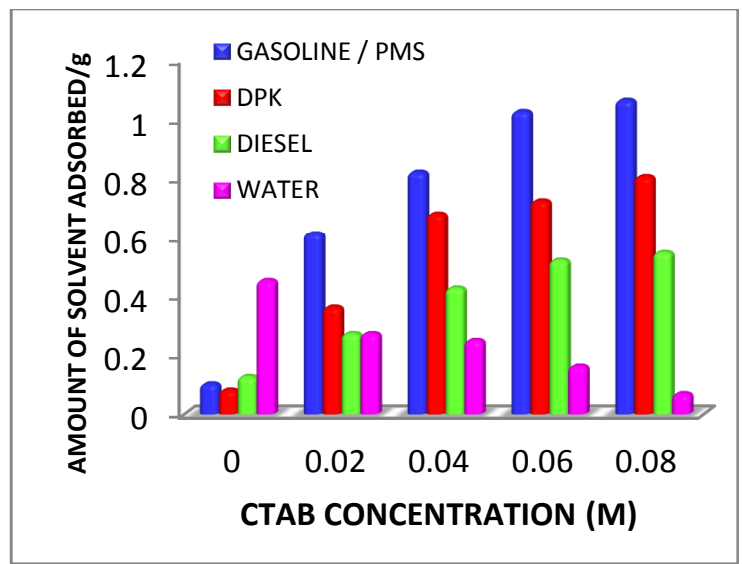

Fig 7: Effect of CTAB concentration on the adsorption capacity of magnesium bentonite using petroleum products and water
The amount of toluene removed from the solution is less than the amount of $m-x y l e n e$ removed as shown in table 1 and 2 . This is as a result of the difference in the molecular weights of the adsorbates, $\mathrm{m}$ - xylene is heavier than toluene, and hence the lighter and more water soluble toluene exhibited an immense inclination to remain in the solution during the adsorption process (Sari et al., 2007).

The result presented in table 2 shows that the value of the adsorption capacity, $\mathrm{q}_{\mathrm{e}}$ increased for the CTAB modified magnesium bentonite. The intercalation of cetyltrimethylammonium bromide (CTAB) between the layers of the bentonite increased the adsorption power, the basal spacing and the organophilicity of the bentonite, thereby increasing its affinity and interaction with organic compounds (m-xylene and toluene).

The values of the rate constant $\left(\mathrm{K}_{2}\right)$ and correlation factor $\left(\mathrm{R}^{2}\right)$ are given in table 2. Linear plots were obtained with high correlation coefficients $\left(\mathrm{R}^{2}\right)$, which are far closer to unity compared to pseudo first order, suggesting that the interaction between the adsorbent and the two adsorbates follow second order mechanism. This observation clearly demonstrates that both m-xylene and toluene competitively adsorbed on the surface of the bentonite, and the rate determining step is bimolecular involving the two adsorbates. The result equally showed that above 120 mins, the plots begin to deviate a little from linearity (Aamir et al., 2017).

Table 1: Parameters obtained from Langmuir and Freundlich adsorption isotherm models

\begin{tabular}{llllll}
\hline & & \multicolumn{2}{c}{ M- Xylene } & \multicolumn{2}{c}{ Toluene } \\
\hline Adsorption & & MMB & UMB & MMB & UMB \\
Isotherm Model & & & & & \\
& Co (mg/L) & 300 & 300 & 300 & 300 \\
Langmuir & $\mathrm{q}_{\mathrm{m}}$ & 17.47 & 9.1 & 16.65 & 7.63 \\
& $\mathrm{~K}_{\mathrm{L}}$ & 0.012 & 0.004 & 0.012 & 0.005 \\
& $\mathrm{R}_{\mathrm{L}}$ & 0.217 & 0.455 & 0.217 & 0.4 \\
& $\mathrm{R}^{2}$ & 0.9357 & 0.9714 & 0.9414 & 0.9677 \\
Freundlich & $\mathrm{K}_{\mathrm{F}}$ & 0.547 & 0.161 & 0.48 & 0.117 \\
& $\mathrm{I} / \mathrm{n}$ & 0.6333 & 0.6193 & 0.6484 & 0.6695 \\
& $\mathrm{R}^{2}$ & 0.9957 & 0.9757 & 0.9953 & 0.9853 \\
\hline
\end{tabular}

$\mathrm{MMB}=$ Modified Magnesium Bentonite, $\mathrm{UMB}=$ Unmodified Magnesium Bentonite. 
Table 2: Parameters obtained from Pseudo first and Pseudo second order adsorption Kinetics models

\begin{tabular}{llcccc}
\hline & & \multicolumn{3}{c}{ M- Xylene } & \multicolumn{2}{c}{ Toluene } \\
\hline kinetics model & & MMB & UMB & MMB & UMB \\
& Co $(\mathrm{mg} / \mathrm{L})$ & 300 & 300 & 300 & 300 \\
Lgergren Pseudo- & $\mathrm{qe}(\mathrm{mg} / \mathrm{g})$ & 11.69 & 9.76 & 11.44 & 9.26 \\
First Order & $\mathrm{K}_{1}$ & 0.0217 & 0.0189 & 0.0767 & 0.0194 \\
& $\mathrm{R}^{2}$ & 0.958 & 0.9374 & 0.9585 & 0.91 \\
Pseudo- Second- & $\mathrm{qe}(\mathrm{mg} / \mathrm{g})$ & 11.69 & 9.76 & 11.44 & 9.26 \\
Order & $\mathrm{K}_{2}$ & 0.0033 & 0.00025 & 0.0027 & 0.00017 \\
& $\mathrm{R}^{2}$ & 0.9938 & 0.9884 & 0.9889 & 0.9494 \\
\hline
\end{tabular}

$\mathrm{MMB}=$ Modified Magnesium Bentonite, UMB = Unmodified Magnesium Bentonite.

Conclusion: The competitive adsorption of $\mathrm{m}-\mathrm{xylene}$ and toluene was successfully carried out using unmodified and CTAB modified magnesium exchanged bentonite. Modified magnesium bentonite has a higher percentage removal and higher adsorption capacity than raw or unmodified magnesium bentonite. m-xylene was removed from the solution more than toluene. CTAB modified magnesium bentonite has proven to be an effective adsorbent for removal of both $\mathrm{m}$ - xylene and toluene from their aqueous solution. Hence water treatment industries and petrochemical industries should utilize this adsorbent for removal of hydrocarbon ( $\mathrm{m}$ - xylene and toluene) from their waste water and effluents.

Acknowledgement: The authors wish to acknowledge the management of Mansid Nigeria Limited, Portharcourt for providing the bentonite used for this research, Jawura environmental service limited Portharcourt where the UV analysis was carried out and the laboratory technologist of energy research centre, University of Nigeria Nsukka, where the FTIR analysis was carried out.

\section{REFERENCES}

Aamir, A; Basim, AAI; Nadhir, AHA; Halim, HR (2017). Adsorption of Toluene and Paraxylene from Aqueous Solution Using Pure and Iron Oxide Impregnated Carbon Nanotubes: Kinetics and Isotherms Study. Hindawi Bioinorganic Chemistry and Applications. Article ID 2853925

Arthur, GC; Robert, WD (2010). Industrial Applications of Bentonite. American Colloid Company, Skokie, Illinois. $272-283$.

Bedin, S; Oliveira, MF; Vieira, MGA; Santos, OAA; Silva, MCG. (2013). Adsorption of Toluene In Batch System In Natural Clay And Organoclay. The Italian Association of Chemical Engineering (32) 313 - 318.

Clarence, SR; Earl, VS (1926). The Minerals of Bentonite and Related Clays and Their Physical Properties. Journal of the American Ceramic Society; 9(2): 7796.

Chikwe, TN; Ewuzie, HE; Ngobiri, NC; Okoye, IP
Eren, E (2008). Removal of Coper Ion Using Modified Unye Clay, Turkey. Journal of Harzard Material, 159: $235-244$.

Hosterman, JW; Patterson, SH (1992). Bentonite and Fuller's Earth Resources of the United States. U.S. Geological Survey Professional Paper 1522. United States Government Printing Office, Washington D.C., USA.

Jorge, VFLC; César, AMA; Marilda, NC; Maurício, AMS; Mohand, B; Osmar, SB (2012). Petrochemicals; Removal of Effluent from Petrochemical Wastewater by Adsorption Using Organoclay. Intech Publication, Shanghai, China. 278- 294.

Komlosi, A; Kuzmann, E; Nagy, NM; Homonnay, Z; Kubuki, S; Konya, J (2007) Incorporation Of Fe In The Interlayer Of Na-Bentonite Via Treatment With $\mathrm{FeCl}_{3}$ in Acetone. Clays and Clay Minerals. (55):1 91-97.

Koyuncu, H; Yildiz, N; Salgın, U; Köroğlu, F; Çalimli, A (2011). Adsorption of o-, m- and p-nitrophenols onto organically modified bentonites. Journal of Hazardous Materials. 185 (2) 1332-1339.

Nourmoradi, H; Khiadani, M; Nikaeen, M (2012). MultiComponent Adsorption Of Benzene, Toluene, Ethylbenzene, And Xylene From Aqueous Solutions By Montmorillonite Modified With Tetradecyl Trimethyl Ammonium Bromide. Journal of Chemistry, Article Id 589354. 1 - 2.

Obi, C; Apemiye, MA (2017). Meta-Xylene Removal from Aqueous Solution Using Surfactant-Modified Bentonite: A Kinetic View. Journal of Chemical Engineering \& Process Technology 8(1): 323 - 328.

Obi, C; Okoye, IP (2015). Absorption Capacity and Time Effect on Polarity Evaluation of Various Solvents Using Natural Bentonite Clay Mineral. Sky Journal of Soil Science and Environmental Management 4(1): $016-019$

Okoye, IP; Obi, C; Otolo, SE (2012). A Study of The Adsorption Kinetics of Chromium Pillared Bentonite Clay Mineral. Journal of Applied Technology in Environmental Sanitation, 2(3), 145 - 154. 
Paiva, LB; Morales, AR (2012). Organophilic Bentonites Based On Argentinean and Brazilian Bentonites. Part 1: Influence of Intrinsic Properties of Sodium Bentonites on the Final Properties of Organophilic Bentonites Prepared By Solid-Liquid and Semisolid Reactions. Brazillian. Journal of chemical Engineering 29(3): 1 -12.

Sari, A; Tuzen, M; Soylak, M (2007). Adsorption of Lead and Chromium from Aqueous Solution on Celtek Clay. Journal of Harzard Material, 144: 41 - 46.
Senturk, BH; Ozdes, D; Gundogdu, A; Duran, C; Soylak, M (2009). Removal of Phenol from Aqueous Solutions by Adsorption onto Organomodified Tirebolu Bentonite; Equilibrium, Kinetic and Thermodynamic Study. Journal of Harzardous Material 172: 353- 362. 